\title{
Pullout Bond Properties of Grout-Filled Mechanical Splice for Precast Concrete Construction
}

\author{
ZHENG Yongfeng ${ }^{1, a}$, GUO Zhengxing ${ }^{1, b^{*}}$ and Ming $\mathrm{Xie}^{2, \mathrm{c}}$ \\ ${ }^{1}$ School of Civil Engineering, Southeast University, Nanjing, China \\ ${ }^{2}$ Shandong Jiayi Architectural Design Co., LTD, Jinan 250101, China. \\ azhyf-fb@163.com, b guozx1956@126.com, ${ }^{c} 187207345 @ q q . c o m$
}

\begin{abstract}
Keywords: grout-filled pipe splice, bond, precast concrete
Abstract. A new type of grouting coupler for rebar splicing was fabricated with common seamless steel pipe by cold rolling technique. Seven splice specimens were prepared with the sleeve and tested under pullout load. The test results have shown that given a proper embedded length, the specimens provided good behaviour of which the ultimate tension load exceeded the required loading capacity specified in ACI318 and JGJ107. The pullout behavior of grout-filled pipe splice are influenced by the inner cavity structure of the sleeve.
\end{abstract}

\section{Introduction}

The original grouted sleeve for rebar splicing was invented by Alfred A. Yee [1] in the late 1960, and consequently increased used in North America in the late 1980's and 1990's .In the past forty years, grout sleeve splicing for rebars got extensive use aroud the word and experienced several severe earthquakes without damage. Recently, the advantages of precast concrete structure such as higher quality control, reducing construction time, little environmental pollution and etc. have been gradually realized in China, and more and more precast buildings were constructed. However, because of the complex configuration and processing technic, the cost of grouted sleeve is much higher than the conventional steel bar coupler used in cast-in-situ concrete structure. This problem to a certain extent hampered the development and widely use of precast construction in China.

Meanwhile, due to the proprietorship, most of research results about the grouted pipe splice are confidential and private. There have been few studies thus far on the bond performance between filler grout and reinforcing bars in grouted splice system. Among the previous studies, Hayashi et al. [2,3] performed monotonic loading test and cyclic loading test on the grouted splice specimens. Einea et al. [4] prepared four types of splice specimens with different grouting connector and performed a monotonic loading test. Based on the test results, they derived the confinement of the sleeve and proposed an equation to calculate the bond strength of the splice. Based on the test results of forty grouted splice specimens failed by the pullout of the spliced bar, Kim [5] proposed an method to estimate the confining stress of the sleeve and the ultimate bond capacity of the splice. Ling et al. [6] introduced two new sleeve (Welded bar sleeve and Tapered head sleeve) and made an experimental study on the behaviour of the grouted splice. Sayadi et al. [7] studied the relationship between interlocking mechanics and bond capacity in the elastic and inelastic segment of the steel pipe splice. Henin and Morcous [8] prepared a new grouted sleeve which featured on their threaded inner surface at one end or at both ends and made a feasibility study.

Although in some of the mentioned investigations, the behaviour of grout sleeve splicing system was studied, but due to the different test parameters, such as type and bonded length of the steelbar, grout properties, the inner cavity structure of the sleeve and etc., the grouted splice may exhibit different behavior and need to be furtherly studied. In this paper, a new type of grouted deformed pipe splice (GDPS) was introduced. The sleeve was fabricated with a seamless steel pipe through cold rolling technology, and featured by its unique configuration. Based on this sleeve, seven coupler specimens were prepared and tested under tensile load. 


\section{Experimental program}

Test specimen. Seven specimens were prepared with GDPS sleeve and smooth sleeve for this experimental study. The sleeve was made of standard seamless steel pipe with outer diameters of 45 $\mathrm{mm}$ and wall thickness of $4 \mathrm{~mm}$, and the specified yield strength of $345 \mathrm{MPa}$. Commercially available $18 \mathrm{~mm}$ deformed bar was used with yield strength of $449 \mathrm{MPa}$ and tensile strength of $605 \mathrm{MPa}$. The average compressive and flexural strengths of the grout at the day of test are 91.8 MPa and 15.1 MPa, respectively.

Two types of grouted sleeves were prepared as shown in Figure 2: type "S" which is a smooth seamless steel pipe without rolling depression; and type " $G$ " represents the GDPS sleeves which processed by specially designed lathe. Its configuration is featured by the concentric ribs on the inner surface and the concentric inverted trapezoid grooves on the outer surface, which can improve the bond strength between the sleeve and inner grout as well as the sleeve and surrounding concrete. The type "S" sleeve specimen were tested as control specimen, for comparison purposes.

The specimens are named with a two component ID according to their variables. For example, in "G345-6d", the first part shows the sleeve type, where the first figure indicates type "S" or type "G" sleeve, the second figure indicates the number of the concentric ribs on each side $(0,2,3$, or 4$)$, and the third and forth figures represents the outer diameter of the sleeve (45); the second part represents the embedded length $(5 \mathrm{~d}, 6 \mathrm{~d}$ or $7 \mathrm{~d})$. Table 1 indicates the designations of the specimens.

The pullout test was then performed on the fatigue machine at a rate of $2 \mathrm{MPa} / \mathrm{s}$ (Fig. 2). During the test, the load and displacement values were recorded using different data acquisition systems.

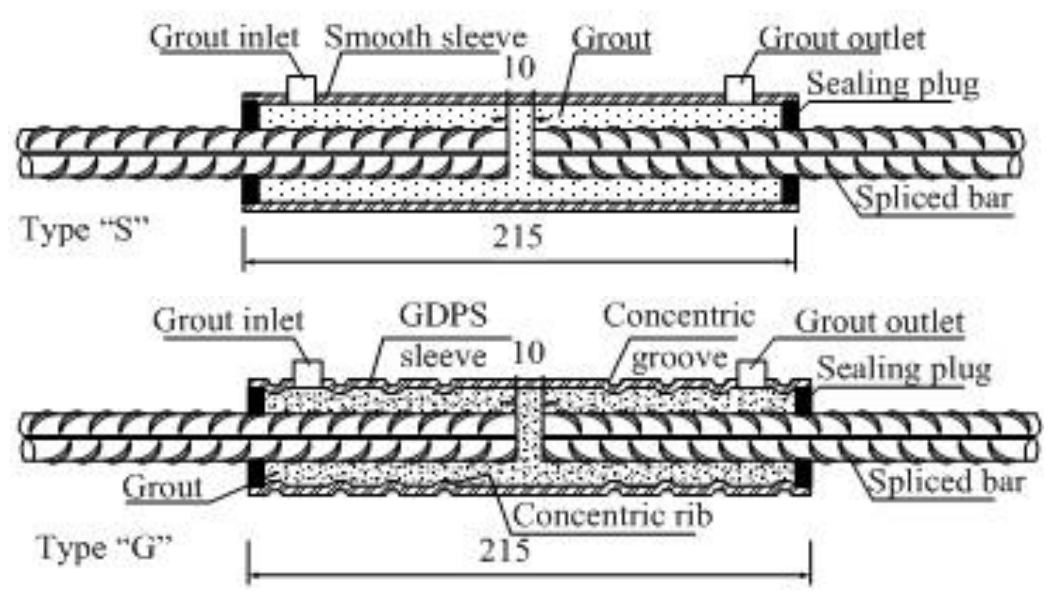

Fig. 1 Two types of the tested bar splice sleeves (mm)

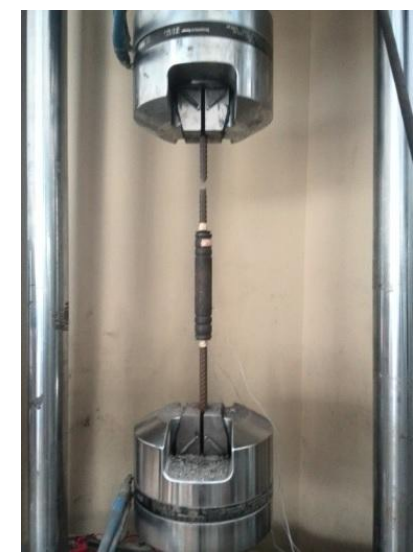

Fig. 2 Test setup

Test results and discussions. Three different failure modes were observed, namely sleeve-grout bond failure, bar-grout bond failure, bar fracture failur (see Fig. 3). Only the type "S" sleeve specimens failed by the pullout of the grout cylinder, this result demonstrates the significant effect of the concentric ribs on preventing the grout slide with the reinforcement. Fig. $3 b$ shows the bar-grout bond failure. Close examination on the end of the sleeve, the failure surface of the grout is similar to the specimen failed by bar fracture (Fig. 3c).

Table 1 list the summary of the test results. The values of bond strength were calculated as the maximum pullout load divided by the surface area of the bar embedded in the grout, or by the contact area between the sleeve and the grout as below:

$$
\begin{aligned}
\tau_{\mathrm{b}} & =P_{\mathrm{u}, \exp } /\left(\pi \cdot d_{\mathrm{b}} \cdot l_{\mathrm{b}}\right) \\
\tau_{\mathrm{s}} & =P_{\mathrm{u}, \exp } /\left[\pi \cdot D_{\mathrm{s}, \text { in }} \cdot\left(0.5 L-L_{1}\right)\right]
\end{aligned}
$$

where $\tau_{\mathrm{b}}, d_{\mathrm{b}}, l_{\mathrm{b}}$ are the bond strength, nominal diameter, and embedment length of the spliced bar respectively; $D_{\mathrm{s}, \text { in }}$ is the inside diameter of the sleeve; $L_{1}$ is the thickness of the sealing plug. From the table, it can be seen that if the bonded length of the spliced bar exceeds 6 times of the diameter, all 
the specimens failed by bar fracture. The strength naturally meet the ACI318 [9] Type 2 splice requriement.

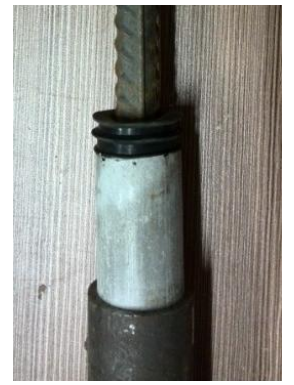

(a) Sleeve-grout bond failure

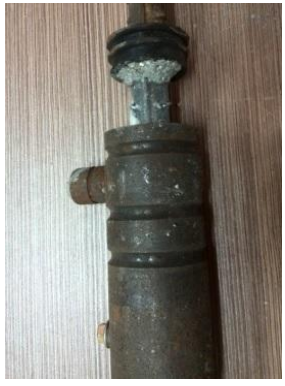

(b) Bar-grout bond failure mode

Fig. 3. Failure mode

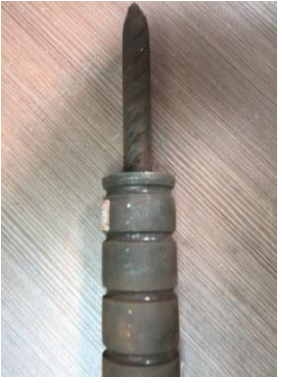

(c) Bar fracture failure

Table 1. Summary of test results

\begin{tabular}{cccccc}
\hline Specimen & $\begin{array}{c}\text { Maximum load, } P_{\mathrm{u}, \exp } \\
{[\mathrm{kN}]}\end{array}$ & $\begin{array}{c}\text { Bond strength, } \tau_{\mathrm{b}} \\
{[\mathrm{Mpa}]}\end{array}$ & $\begin{array}{c}f_{\mathrm{u}} \\
f_{\text {byk }}\end{array}$ & $\begin{array}{c}f_{\mathrm{u}} \\
f_{\text {buk }}\end{array}$ & Failure mode \\
\hline S045-5d & 79.5 & 7.60 & 0.78 & 0.58 & $\begin{array}{c}\text { Sleeve-grout bond } \\
\text { failure }\end{array}$ \\
G345-6d & 144.8 & 23.70 & 1.42 & 1.05 & Bar fracture failure \\
G445-6d & 149.9 & 24.54 & 1.47 & 1.09 & Bar fracture failure \\
G445-7d & 144.9 & 20.34 & 1.42 & 1.05 & Bar fracture failure \\
G245-5d & 140.1 & 27.53 & 1.38 & 1.02 & Bar-grout bond failure \\
G345-5d & 147.7 & 29.02 & 1.45 & 1.07 & Bar-grout bond failure \\
G445-5d & 144.6 & 28.41 & 1.42 & 1.05 & Bar-grout bond failure \\
\hline
\end{tabular}

\section{Comparison of the pullout behavior}

Bond capacity of the grouted splice. Fig. 5 presents the comparison of bond capacity for the specimens with the same variations except the quantities of the concentric rib. When the number of the rib increased from two to three, the ultimate bond capacity increased from $140.1 \mathrm{kN}$ to $147.7 \mathrm{kN}$. However, as the number increased to four, the bond capacity of the splice reduced from $147.7 \mathrm{kN}$ to $144.6 \mathrm{kN}$. It is likely that the interlocking mechanism in the elastic segment, which cause bond reduction in this region (Sayadi et al. 2014 2015). For this reason, it can be concluded that providing interlocking in the elastic region of sleeve is not a reasonable way to enhance bond capacity.

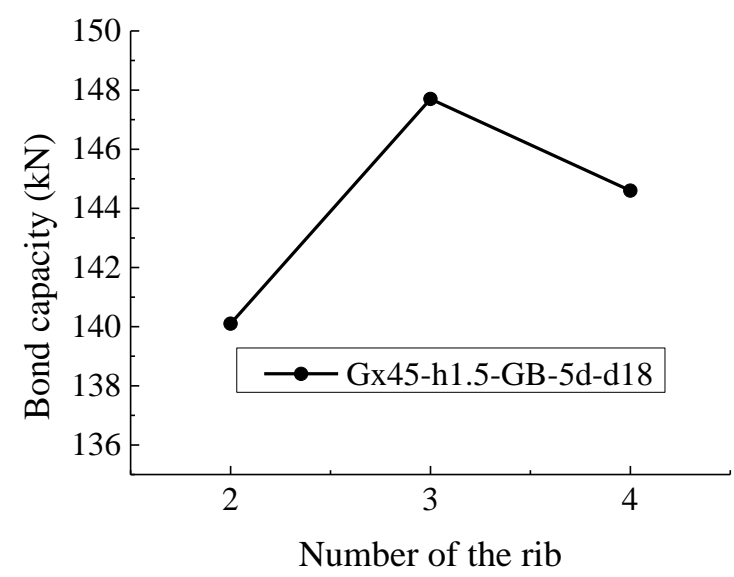

Fig. 4 Maximum load-number of the rib relationship for the splice specimen

Load-displacement relationship of the grouted splice. Fig. 6 shows the comparison of the load-displacement response of the specimens with different number of ribs, the abscissa represents the relative displacement between the champing fixtures. For easy comparison, different ratio of the abscissa is adopted. Fig. 4(a) shows that increasing the number of concentric rib led to a smaller displacement, i.e., a higher stiffness. At $60 \mathrm{kN}$ load, the stress in the bar is approximately $0.6 f_{\text {byk }}$, the 
displacement of the specimens with two, three and four ribs is $1.20 \mathrm{~mm}, 1.06 \mathrm{~mm}$ and $1.04 \mathrm{~mm}$, respectively.
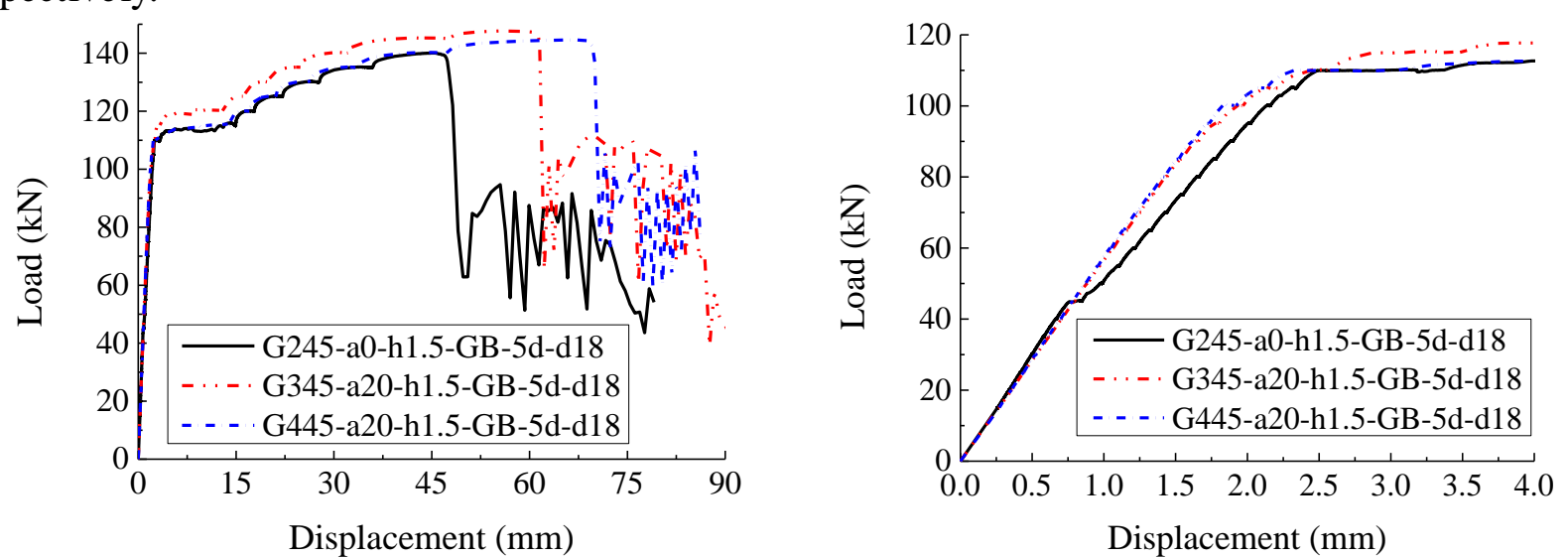

Fig. 5 Comparison load-displacement relationship for the splice with different rib number

\section{Conclusion}

This paper investigated the behaviour of a new grouted pipe splice under tensile load. The results of this experimental program proved the feasibility of GDPS sleeve and the following particular conclusion could be drawn:

(1) The tensile capacity of the splice specimens prepared with embeded length of 6 times bar diameter could exceed the ACI318 (2011) requirement for Type 2 splice.

(2) the increase of the quantytity of the concentric rib could improve the bond capacity and stiffenss of the splice. Nevetherless, the rib should be set in the inelastic segment of the sleeve, outherwise would result in a decline of the bond capacity.

\section{Acknowledgements}

The authors gratefully acknowledge financial support from the National "Twelfth Five-Year" Plan for Science and Technology (No.2011BAJ10B03).

\section{References}

[1] Yee AA. Splice sleeve for reinforcing bars. US Pat. 3540, 763. (1968)

[2] Hayashi, Y., et al. Bond stress-slip characteristic of reinforcing bar in grout-filled coupling steel sleeve. Proceedings, Japan Concrete Institute 15.2 (1993): 256-270.

[3] Hayashi, Y., et al. Mechanical Performance of Grout-Filled Coupling Steel Sleeves under Cyclic Loads. Journal of Structural and Construction Engineering, Architectural Institute of Japan 496 (1997): 91-98.

[4] Einea, Amin, Takashi Yamane, and Maher K. Tadros. Grout-filled pipe splices for precast concrete construction. PCI journal 40.1 (1995): 82-93.

[5] Kim, Hyong-Kee. Bond Strength of Mortar-filled Steel Pipe Splices Reflecting Confining Effect. Journal of Asian Architecture and Building Engineering 11.1 (2012): 125-132.

[6] Ling, Jen Hua, et al. Behaviour of grouted pipe splice under incremental tensile load. Construction and Building Materials 33 (2012): 90-98.

[7] Sayadi, Ali A., et al. The relationship between interlocking mechanism and bond strength in elastic and inelastic segment of splice sleeve. Construction and Building Materials 55 (2014): 227-237.

[8] Henin, Eliya, and George Morcous. Non-proprietary bar splice sleeve for precast concrete construction. Engineering Structures 83 (2015): 154-162.

[9] ACI Committee 318. Building code requirements for structural concrete (ACI 318-11) and commentary. American Concrete Institute; 2011. 